\title{
A importância da poesia e da imaginação
}

\author{
Maria Cristina Castilho Costa \\ Professora Livre-Docente do Departamento de Comunicações e Artes da Escola \\ de Comunicações e Artes da Universidade de São Paulo, \\ Editora da Revista Comunicação \& Educação \\ E-mail: criscast@usp.br
}

Resumo: A autora relembra o passado de jovem leitora interessada em obras menosprezadas pela escola e o constrangimento que marcou sua adolescência por conta de ...E o vento levou, clássico exemplar de livro censurado pela escola do passado e homônimo do filme consagrado pelo cinema até os dias de hoje. Assim, comemora com os leitores a mudança dos tempos e como a educação atualmente vê com bons olhos o interesse que os alunos demonstram pelos meios de comunicação, pela leitura de romances e de quase toda literatura. Enfatiza como essa revolução aproxima alunos de professores e o ensino daquilo que efetivamente preocupa e atrai os estudantes.

Palavras-chave: literatura, cinema, educação, comunicação, linguagem.

Abstract: The author remembers her past of young reader interested in literary works underestimated by school and the embarrassment that has marked her youth because of Gone with the Wind, classic example of book censored by the old school and homonymous of the motion picture acclaimed until nowadays. Thus, she commemorates with readers the change of times and how education watches with good eyes the interest of students by media, reading novels and almost all sorts of literature. She emphasizes how this revolution approaches students to teachers and teaching to what effectively concerns and attracts students.

Keywords: literature, cinema, education, communication, language.

Em 1962, uma aluna do então curso ginasial, etapa que hoje corresponde às quatro últimas séries (de $5^{\mathrm{a}}$ a $8^{\mathrm{a}}$ ) do Ensino Fundamental, de prestigiada escola particular da cidade de São Paulo, lia um romance durante a aula de português. Tratava-se de uma tradução do famoso Gone with the Wind (...E o vento levou), de Margareth Mitchell, narrando as desventuras de uma jovem norte-americana, Scarlett O'Hara, na época da Guerra de Secessão estadunidense (1861-1865). Em meio aos grandes conflitos daquela que foi a maior revolução ocorrida nos Estados Unidos, a jovem protagonista enfrentava inúmeros problemas pessoais, como administrar suas dúvidas sentimentais e salvar a propriedade herdada de seus pais, devastada nos embates entre os sulistas e os federados; tarefas difíceis para uma moça educada nos princípios conservadores do sul dos Estados Unidos, no século XIX. ...E o vento levou constitui longo e envolvente romance que vem emocionando diversas gerações. Publicado em 1929, foi adaptado para o 
cinema $^{1}$, tornando imortais as atuações de Vivien Leigh, como Scarlett O'Hara, e Clark Gable, como Rett Butler, seu par amoroso. Mereceu 10 Oscars e, com Branca de Neve, foi um dos filmes mais vistos no mundo.

Mas voltemos a nossa jovem aluna que, na adolescência, deliciava-se com as reviravoltas de ...E o vento levou em plena aula de português. Imersa na leitura, não percebeu quando a professora se dirigiu a ela durante uma explanação. Sem responder às duas vezes em que foi chamada, tornou-se evidente que a moça não acompanhava a aula como esperado. A professora levantou-se de sua mesa e resoluta caminhou em direção à aluna. Ao perceber o que a jovem lia, escandalizou-se e, brandindo o grosso volume no ar, admoestou-a. O resto é fácil de imaginar - foram ambas à Coordenação Pedagógica, à Direção e, finalmente, aos pais da garota, chamados à escola para uma reunião. Impunhase um castigo à aluna indisciplinada - nada mais nada menos que a retenção do livro, impedindo-se o término da leitura inconveniente e a descoberta de como Scarlett O'Hara resolvera seus problemas. Porém, diante do proposto, os pais da garota lembraram que o livro fora retirado por empréstimo de uma biblioteca pública e que deveria ser devolvido, uma vez tratar-se de obra esgotada e não haver possibilidade de se ressarcir a biblioteca pela perda. Diante desse argumento, a Direção decidiu relaxar o castigo, entregando o livro ao casal, incumbido de encaminhá-lo à biblioteca sem que a filha tornasse a lê-lo. Com esse procedimento, professores, coordenadores e diretores castigavam a indisciplina da aluna, assim como o tempo perdido com uma obra considerada popular, destituída de grandes méritos literários ou filosóficos. Para eles, o único interesse que as desventuras de Scarlett O'Hara poderiam despertar era o mero entretenimento, que nada acrescentaria ao desenvolvimento físico ou espiritual da aluna.

Hoje essa garota tem muitos anos de vida e muitas séries de cursos concluídos; já devorou um sem-número de romances e também escreveu ensaios e trabalhos acadêmicos, mas jamais esqueceu a sensação de culpa experimentada por estar lendo no Ginásio, com imenso interesse, um romance não recomendado durante a aula de português. Por essa razão, é com enorme prazer que ela pode, através da revista Comunicação \& Educação, perceber que os tempos mudaram e que a educação hoje vê com bons olhos o interesse que os alunos demonstram pelos meios de comunicação, pela leitura de romances e de quase toda literatura. E, com alegria, ela percebe que por aqui também se viveu uma revolução que busca aproximar alunos de professores e o ensino daquilo que efetivamente preocupa e atrai os estudantes.

Sabemos que aquilo que nos motiva, interessa ou mobiliza está, de alguma forma, respondendo a necessidades imperiosas que exigem esclarecimento, informação ou mera atenção. Também temos certeza de que só a informação que reage a esses impulsos é processada e atua como agente transformador de nossas estruturas profundas. E, além de tudo isso, advogamos que não haja (Gone With The Wind). Direção Victor Fleming. EUA: MGM, 1939. divórcio entre a vida cotidiana do aluno fora da escola com o que ele realiza ou aprende em sala de aula. Essa visão mais abrangente e menos acadêmica do 
A importância da poesia e da imaginação - Maria Cristina Castilho Costa

ensino é que permite que romances, histórias em quadrinhos, filmes e vídeos, CDs e computadores sejam utilizados como fonte de motivação e aprendizagem. Acreditamos, como Gaston Bachelard sustenta em sua obra A poética do espaço, que a imaginação é, nesse sentido, a potência maior da natureza humana ${ }^{2}$, capaz de dar um novo sentido à vida, à linguagem e até à lógica.

Sabemos que o conhecimento não se baseia apenas naquilo que transita por nossa racionalidade, e que a mente é feita de muitas outras fontes de percepção e conhecimento - os sonhos, a imaginação, o devaneio, a lembrança. É necessário motivar e acionar todas essas faculdades mentais ao se considerar os processos educativos. É preciso lidar com a beleza, com a poesia, com o interesse e com a motivação. Isso nos remete a um trecho particularmente belo de Jorge Luis Borges acerca da descoberta da poesia. Diz ele:

E quando o fato de que a poesia, a linguagem, não era somente um meio de comunicação, mas também podia ser uma paixão e um prazer - quando isso me foi revelado, não acho que tenha aprendido as palavras, mas senti que algo acontecia comigo. Acontecia não com meu simples intelecto, mas com todo o meu ser, minha carne e meu sangue ${ }^{3}$.

O que trazemos neste número da revista Comunicação \& Educação para nossos leitores espelha toda essa conquista - repensar a educação como experiência integral do conhecimento, aproximar os conteúdos aprendidos da sensibilidade e percepção do sujeito, levar em conta na educação tudo que rodeia o aprendiz e habita sua mente e, finalmente, pensar o aluno como um ser integral e vivo - não um arquivo de informações. Como veremos, cada artigo deste número coloca em ação parte dessas idéias e as transforma em debate, orientação ou experiência. Vamos a eles, então.

\section{A IMPRENSA EM PAUTA}

Diversos artigos deste número da revista Comunicação \& Educação dedicamse ao estudo da imprensa. Liriam Sponholz analisa a forma como jornalistas brasileiros e estrangeiros apercebem-se da realidade que os cerca e buscam interpretá-la e transformá-la em notícia. A autora mostra as dificuldades envolvendo esse processo, procurando sensibilizar o leitor para a difícil relação realidade-notícia-imprensa.

Autora do artigo internacional, Jamile Dalpiaz faz uma interessante avaliação de como os jornais britânicos The Guardian, The Independent e The Times noticiaram os dois turnos do processo de reeleição de Lula para a Presidência da República, em 2006. Com esse estudo, ela apreende os aportes ideológicos destes jornais e analisa como a realidade brasileira foi apresentada aos leitores britânicos.

Afastando-se da palavra escrita, mas ainda no campo da imprensa, Waldomiro Vergueiro e Roberto Elísio dos Santos trazem para nós considerações a respeito da mais antiga revista de quadrinhos brasileira - O Tico-Tico, conhe-
2. BACHELARD, Gaston. A poética do espaço. São Paulo: Martins Fontes, 1988. p. 18.

3. BORGES, Jorge Luis. Esse ofício do verso. São Paulo: Cia. das Letras, 2000. p. 14. 
comunicação \& educação • Ano XIII • Número 2 - maio/ago 2008

cida de todos nós que já não somos tão crianças. Lançada por Bartolomeu de Souza e Silva, em 1905, a 200 réis o exemplar, circulou até a década de 1960, quando começou sua decadência, em razão da competição acirrada com a televisão. Além de uma proposta pedagógica importante, baseada no civismo e em valores morais da sociedade, a revista $O$ Tico-Tico cumpriu ainda outra missão: serviu de espaço para que diversos desenhistas e humoristas brasileiros desenvolvessem sua arte, concorrendo com um sem-número de revistas similares estrangeiras. Isso nos mostra como, para além do mero entretenimento, esses periódicos podem cumprir funções sociais e educativas.

\section{TENDO EM VISTA O AUDIOVISUAL}

Diversos autores que têm contribuído com a revista Comunicação \& Educação abordam as questões relativas ao uso do audiovisual em sala de aula - as vantagens e as dificuldades técnicas e pedagógicas. Eloiza Gurgel Pires trata também desse tema, mostrando a crescente importância dessas atividades pedagógicas em vista da particularidade e complexidade da sociedade contemporânea.

Ainda no campo da produção audiovisual, Paulo de Jesus e Nara Silvana Albuquerque Patriota trabalham com as teorias da recepção para estudar as relações entre o rural e o urbano mediado pela comunicação televisiva. O artigo é um relato da interessante pesquisa realizada com os alunos do curso de Formação Profissional de nível médio - Técnico em Agropecuária (TA), do Colégio Agrícola Dom Agostinho Ikas, São Lourenço da Mata - PE, tendo por objetivo entender como o seriado Malhação é percebido por esses jovens. Procura-se avaliar a influência dos signos e mensagens urbanas no imaginário juvenil próximos ao mundo rural.

$\mathrm{Na}$ mesma vertente, percebendo e valorizando a influência da televisão no cotidiano dos alunos e da sociedade em geral, Maria Isabel Orofino aborda a telenovela como uma obra aberta. Discutindo o poder autoral da indústria cultural e sua hegemonia sobre o espectador, a autora propõe outra leitura - a telenovela como uma narrativa cotidiana e coletiva que é construída dos dois lados da tela.

Na seção Depoimento, também é a televisão e o vídeo que estão em pauta. Paula Saldanha, um rosto conhecido dos telespectadores, fala de sua carreira e de como acabou se envolvendo com questões de educação e, mais especificamente, de educação ambiental. Apreciadora de literatura, pedagoga por vocação - "A idéia de uma escola livre, dinâmica, do maternal à universidade estava firme na minha cabeça", nos conta -, estreou na televisão em 1974, no programa Fantástico, a convite da rede Globo. Sentiu-se realizada: "Mas que fenômeno fabuloso este da televisão! Em lugar de dar meu recado para milhares de jovens, passei a me comunicar com milhões de pessoas instantaneamente". Criou programas especiais, como o Globinho, primeiro telejornal para crianças e jovens da TV brasileira, e outros com a mesma preocupação, sempre unindo jornalismo e educação. Você não pode perder esse Depoimento. 
A importância da poesia e da imaginação • Maria Cristina Castilho Costa

\section{MEIOS DIGITAIS E GAMES}

Pesquisa realizada entre 2003 e 2004, na Escola Técnica do Vale do Itajaí (ETEVI), ligada à Furb - Universidade Regional de Blumenau, mostrou o potencial das mídias digitais e dos games para o desenvolvimento de experiências pedagógicas. Quem nos conta a respeito é Dulce Márcia Cruz e Paulo César Abdalla Ilha, que acompanharam o planejamento de professores de diversas disciplinas para o uso do game SimCity 4, em suas atividades didáticas. Trata-se de importante ferramenta a serviço da educação e da comunicação.

\section{A IMPORTÂNCIA DA MEMÓRIA}

Dois artigos envolvem a importância que se atribui hoje à memória. O primeiro deles fala a respeito do Arquivo Miroel Silveira, constituído dos processos de censura prévia ao teatro, pertencentes ao Serviço de Censura da Divisão de Diversões Públicas do Estado de São Paulo. Esses documentos, que guardam a memória do teatro paulista e a memória da censura, estão sob guarda da Biblioteca da Escola de Comunicações e Artes da USP e são estudados por um grupo de pesquisadores reunidos pelo projeto temático A cena paulista: estudo da produção cultural de São Paulo, de 1930 a 1970, a partir do AMS. O artigo relata os trâmites da censura, levando os leitores a refletir sobre a pertinência ou não dos processos censórios. Essa discussão só se tornou possível porque há um trabalho de resgate da memória arquivada nessa documentação.

A memória também foi a solução encontrada por Leda Márcia Arashiro, diante da constatação de que um dos problemas da universidade para a qual trabalha era a falta de comunicação entre departamentos, professores, alunos, familiares e a alta direção da instituição. Carente de um ecossistema comunicativo, conforme proposto por Jésus Martín-Barbero, as atividades pedagógicas de diferentes unidades da instituição permaneciam independentes e isoladas, dificultando a criação de uma cultura na organização. Para iniciar um processo de entrosamento capaz de gerar integração entre as partes desse todo, Leda propôs um Projeto de Comunicação constituidor da memória da universidade. Ela acredita que o próprio processo de organização e construção do memorial poderia trazer, se bem conduzido, a construção de um ecossistema comunicativo saudável.

\section{ENTRE POESIA E FILOSOFIA}

Dois artigos falam de filosofia e poesia. O primeiro refere-se à entrevista de Yves Schwartz concedida à Roseli Fígaro, na qual o entrevistado conta a respeito de suas pesquisas e de seus estudos envolvendo ergologia e filosofia. Diretor do Departamento de Ergologia da Universidade de Provence, seus trabalhos têm contribuído significativamente com diferentes campos do saber, entre eles a educação. 
comunicação \& educação • Ano XIII • Número 2 • maio/ago 2008

Na seção poesia, o espaço é todo destinado ao centenário da morte de Machado de Assis, que se comemora neste ano. Não é preciso lembrar o quanto sua obra é importante para quem estuda a comunicação, ou para quem trabalha com a educação. Também não é preciso lembrar como sua contribuição vem ao encontro de tudo que aqui defendemos - o respeito por nossa cultura e pela educação.

Encerrando nossa Apresentação e falando ainda sobre poesia, nada mais justo do que mencionar o Museu Goeldi, apresentado na seção Serviços - uma poesia escrita com tijolos, cimento, utopia e natureza. Vale a pena conhecer! 